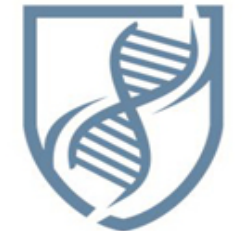

Journal of Bioscience and Applied Research

\section{JBAAR}

WWW.JBAAR.ORG

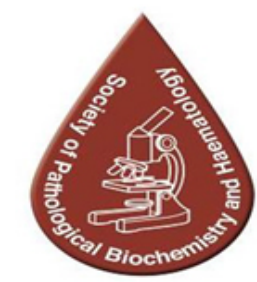

\title{
Serum hyaluronic acid as non invasive biomarker to predict \\ liver fibrosis in viral hepatitis patients
}

\author{
Ayman E. El Agroudy ${ }^{1}$, Mohamed S. Elghareb ${ }^{2}$, Emad H. Elshahat ${ }^{3}$, \\ Ezar H. Hafez ${ }^{4}$, Tamer A. Addissouky ${ }^{5}$ \\ 1 ( Department of Medical Biochemistry, Faculty of Medicine, Mansoura University, Mansoura, Egypt ); ${ }^{2,5}$ ( Department \\ of Chemistry, Faculty of Science, Port Said University, Port Said, Egypt ); 3 (Gastrointestinal Surgery Centre, Faculty of \\ Medicine, Mansoura University, Mansoura, Egypt); ${ }^{4}$ (Department Of Zoology, Faculty of Science, Tanta University, \\ Tanta, Egypt); \\ (Corresponding author e.mail. tedesoky@gmail.com)
}

\begin{abstract}
Fibrosis is a hallmark histologic event of viral hepatitis and is characterized by the excessive accumulation and reorganization of the extracellular matrix (ECM). The gold standard for assessment of fibrosis is liver biopsy. As this procedure has various limitations, including risk of patient injury and sampling error. Serum Hyaluronic acid as non invasive marker for liver fibrosis is desirable. The present study aims to determine the serum hyaluronic acid (HA) levels as biochemical marker of hepatic fibrosis and cirrhosis and correlate it with the degree of hepatic fibrosis. Serum HA level in chronic hepatitis patients $(n=60)$ are divided into two groups, group1: included 30 patients positive for anti-HCV (antibodies), group 2 included 30 patients positive for HBsAg, and controls $(n=10)$ were assessed by ELISA and liver histopathological parameters were evaluated by the modified Knodell score and microscopic examination of liver biopsies from patients. Individuals in healthy control group have normal levels of HA (mean 14.3, SD: 5.5) while the levels of HA were elevated in patients of HCV alone (mean 103.6 \pm 28.0 ) and in patient of HCV (mean 104.5 \pm 37.5).Also levels of HA were poorly elevated in HBV alone (mean 62.2 \pm 15.5) and in HBV (mean 45.8 12.4). showed that serum HA levels are well correlated with HAI in patients of HBV \& HCV groups where, there was significant increase in HA levels by increase of HAI
\end{abstract}

by liver biopsy $\mathrm{P}<0.001$.HA levels and stages of fibrosis were well correlated in patients of HBV and HCV group. Where, this is a significant increase in HA levels when Considering F0 to F6 scores by liver biopsy ( $\mathrm{P}<0.001)$. Serum HA is a useful non-invasive marker of liver fibrosis. There is a strong positive correlation between serum HA levels and degree of liver fibrosis. The concentration of serum HA rises according to progression of liver fibrosis.

Keywords: Viral Hepatitis; Fibrosis; Hyaluronic acid; Liver biopsy; Histological activity index.

\section{Introduction}

Hepatic fibrosis is a complex and dynamic process that includes an increase in extracellular matrix components, activation of cells producing matrix materials, cytokine release and tissue remodeling. The extracellular matrix comprises collagenous and noncollagenous proteins (laminin, Hepatic fibrosis is a complex and dynamic process that includes an increase in extracellular matrix components, activation of cells producing matrix materials, cytokine release and tissue remodeling. The extracellular matrix comprises collagenous and non-collagenous proteins (laminin, proteoglycans and elastin) and hyaluronic acid (HA), which are similar qualitatively but different quantitatively 
from those in normal liver. The synthesis and deposition of these components increase during fibrogenesis. (Gressner and Bachem, 1990) A fraction of these compounds or their split products is released into the systemic circulation, leading to an increase in their serum concentration (Gressner, 1987) being potential markers of the fibrotic process (Plebani and Burlina, 1991) Hyaluronic acid is an unbranched high molecular weight polysaccharide that is widely distributed in the extracellular spaces. Gressner (1987) reported that part of the HA enters the general circulation via the lymphatic system and is rapidly cleared and degraded mainly in the hepatic sinusoidal endothelial cells by way of specialized hyaluronan receptors. Fraser et al., (1981) and EngstormLaurent et al., (1985) reported that a fibrotic liver shows both relative and absolute increase in hyaluronic acid. Nyberg et al., (1988) mentioned that circulating HA measurement may be helpful in differentiating noncirrhotic from cirrhotic liver, for monitoring liver function (Alberti et al., 1992, Wong et al., 1995) and for evaluating the extent of liver fibrosis (Wong et al., 1998,Plebani and Burlina, (1991). These studies have mainly been conducted in patients of chronic liver disease. Hepatitis C and hepatitis $\mathrm{B}$ viral infections are leading cause of chronic liver disease in Pakistan. Hamid et al., (2007) reported that the natural course of the disease process is often sub clinical and at present, conventional biochemical liver function tests and ultrasound scan are unreliable in assessing and monitoring the progression of liver fibrosis in these predominantly(Wong V et al., 1995) asymptomatic patients. Alberti et al., (1992) showed a significant proportion of asymptomatic patients with chronic hepatitis $\mathrm{B}$ and hepatitis $\mathrm{C}$ infections have underlying liver fibrosis or unsuspected cirrhosis. Silva et al., (2004) reported that Liver biopsy is the gold standard method to assess disease activity and fibrosis (Wong et al., 1995) but it is an invasive procedure and may cause uncontrolled bleeding in patients with liver disease. Moreover, there may be certain contraindications for liver biopsy in some patients as well as sampling errors during the procedure. There is a dire need for a non-invasive reliable biochemical serum marker of liver fibrosis, which could be used to monitor patients with chronic liver disease thus reducing the need for repeated liver biopsies (McHutchinson et al., 2000). HA is considered to be a highly specific marker in these patients. McHutchinson et al., (2000) showed that quantitative measurement of HA level in the serum can also be used as useful tool for the assessment of the degree of liver fibrosis and cirrhosis (Bramley et al., 1991). The aim of this study was to determine and correlate serum HA levels with degree of hepatic fibrosis and cirrhosis in chronic hepatitis B and C patients.

\section{Materials and Methods}

\section{Subjects}

This study was conducted on 60 chronic viral hepatitis patients and 10 healthy individuals attending out patients' clinic of Gastrointestinal Surgery Centre, Mansoura University for follow up. According to viral hepatitis markers, subjects were divided into 2 groups: Group 1: included 30 patients, they were positive for antiHCV (antibodies). Group 2: included 30 patients, they were positive for HBsAg .Blood and liver biopsy tissue specimen samples were obtained from studied patients and were subjected to the following lab- tests: 1 . Immunological assays.2. Biochemical assays. -3 . Molecular biology techniques. -4. Tissue Histological assays.

\section{Blood sampling:}

Five ml venous blood sample were withdrawn from every subject by aseptic venipuncture from an anticubital vein in a fasting state. The blood was left to clot in incubator for $15 \mathrm{~min}$. then centrifuged and the separated serum was collected in sterile tube; liver function tests including serum ALT and AST, serum ALB (Heidelbaugh and Bruderly., 2006)., Detection of anti-HCV antibody using enzyme linked immunosorbentassay (ELISA) :Antibodies to hepatitis $\mathrm{C}$ virus (HCV) were qualitatively determined by using ETI-AB-HCVK-3 (P00626) Sorin Biomedica kit (Sorine Biomedica, Diagnostic Division, 1304, Suluggia, Vercelli, Italy) (Rihn et al., 2000). Pathological processing for liver biopsy specimens was as follows, 4 u sections were prepared from paraffin blocks and stained for hematoxyline and eosin stain ( $\mathrm{H} \& \mathrm{E})$, massontrichrom, reticulin, periodic acid Schiff stain (PAS) and PAS- diastase stains (Bancroft and Stevens., 1975). Prepared slides from liver biopsy specimens were examined. Degree of stage of fibrosis were assessed according to (Knodell et al., 1981).Histological activity index (HAI) was based upon assessment of portal inflammatory infiltrate, interface hepatitis and parenchymal necrosis, with score range from 0-18. Fibrosis was scored separately on a scale of $0-6$, corresponding to absent fibrosis up to cirrhosis.

\section{Statistical Analysis:}

Data were obtained using Statistical package for social Sciences (SPSS) version 19.0 software. Data were expressed as means \pm standard deviation (SD) .Results of HCV patients and control subjects were performed using chi- square analysis, way a nova, and independent t-test. Correlation between parameters was determined by Pearson's correlation coefficient (r). Chi square and odds ratio were calculated with $95 \%$ confidence interval .A pvalue less than 0.05was considered statistically significant. 


\section{Results}

Table (1): showed the biochemical characteristics of healthy group. The healthy individuals in this group had normal levels of serum ALT (mean: 23.9, DS: 6.27), AST (mean: 20.8, SD: 5.69) and serum albumin (mean: 4.3, SD: 0.21).Table (2): showed the biochemical characteristics of HBV group. Patients in this group had normal levels of ALT (mean: 28.1, SD: 5.0), serum AST (mean: 25.6, SD: 4.86) and serum albumin (mean: 4.4, SD: 0.29) .Table (3): showed the biochemical characteristics of HCV group. Patients in this group had high levels of ALT (mean: 86.9, DS: 56.7), serum AST (mean: 67.0, SD: 44.2) and serum albumin (mean: 4.3, SD: 0.31). Table 4: showed levels of $\mathrm{HA}$ in serum samples of the studied groups. Individuals in healthy control group have normal levels of HA (mean 14.3, SD: 5.5) while the levels of HA were elevated in patients of HCV alone (mean103.6 \pm 28.0 ) and in patient of HCV (mean 104.5 \pm 37.5). Also levels of HA were poorly elevated in HBV alone (mean 62.2 \pm 15.5) and in HBV (mean 45.8 \pm 12.4) All patients of HCV group were positive for anti-HCV antibodies, while all individuals of healthy group and HBV group were negative for antiHCV antibodies. Table 5 showed no significant difference was observed between HCV and HBV group regarding level of serum HA. Comparison between mild fibrosis and significant fibrosis regarding to HA levels showed highly significant difference $(\mathrm{P}<0.001)$ in both HBV \& HCV groups (Table 6).

Molecular biology of HBV and HCV: Detection of HBV-DNA by PCR HBV-DNA was determined by PCR using primers from pre-s/s region. Pre-s/s specific primers amplify a fragment, which extends between nt 1679 and nt 2254; the amplification product shows a 575bp band which indicates a positive amplification of the pre $\mathrm{s} / \mathrm{s}$ region (figure 1). HBV-DNA was detected in all patients of HBV group and Detection of HCV-RNA by PCRHCVRNA was determined by RT-PCR using primers from 5, -UTR of the viral genome. The size of the amplifies PCR product was determined using agarose gel electrophoresis and DNA marker. The positive HCV - RNA cases gave a band at molecular weight 150pb (Figure 2). HCV-RNA was detected in all patients of HCV group.
Table 1: Biochemical characteristics of chronic hepatitis B (HBV group $n=30$ )

\begin{tabular}{|l|l|l|l|}
\hline \multicolumn{1}{|c|}{ Biochemical parameters } & Mean & SD & Range \\
\hline Serum ALT $(\mathrm{u} / \mathrm{ml})$ & 23.9 & 6.27 & $13-34$ \\
\hline Serum AST $(\mathrm{u} / \mathrm{ml})$ & 20.8 & 5.69 & $11-29$ \\
\hline Serum Albumin $(\mathrm{g} / \mathrm{dl})$ & 4.38 & 0.21 & $4.1-4.8$ \\
\hline
\end{tabular}

Table 2: Biochemical characteristics of healthy group $(\mathrm{n}=$ 10)

\begin{tabular}{|l|l|l|l|}
\hline Biochemical parameters & Mean & SD & Range \\
\hline Serum ALT $(\mathrm{u} / \mathrm{ml})$ & 86.9 & 56.7 & $18-280$ \\
\hline Serum AST $(\mathrm{u} / \mathrm{ml})$ & 67.0 & 44.2 & $25-200$ \\
\hline Serum Albumin $(\mathrm{g} / \mathrm{dl})$ & 4.34 & 0.31 & $.8-5.1$ \\
\hline
\end{tabular}

Table 3: Biochemical characteristics of chronic hepatitis $\mathrm{C}(\mathrm{HCV}$ group $\mathrm{n}=30)$

\begin{tabular}{|l|l|l|l|}
\hline \multicolumn{1}{|c|}{ Biochemical parameters } & Mean & SD & Range \\
\hline Serum ALT $(\mathrm{u} / \mathrm{ml})$ & 28.1 & 5.03 & $19-39$ \\
\hline Serum AST $(\mathrm{u} / \mathrm{ml})$ & 25.6 & 4.86 & $14-35$ \\
\hline Serum Albumin $(\mathrm{g} / \mathrm{dl})$ & 4.40 & 0.29 & $3.9-5.0$ \\
\hline
\end{tabular}


Table4: Characteristics of serum hayluronic acid among the studied groups

\begin{tabular}{|c|r|r|r|}
\hline \multirow{2}{*}{ Studied groups } & \multicolumn{3}{|c|}{ S. Hayluronic acid } \\
\cline { 2 - 4 } & Mean & SD & Range \\
\hline Healthy control & 14.33 & 5.5 & $11-50$ \\
\hline HCV group & & & \\
HCV patients (n=30) & 103.6 & 28 & $10-460$ \\
\hline HBV group & & & \\
HBV patients (n=30) & 62.2 & 15.5 & $13-273$ \\
\hline
\end{tabular}

Table 5: Comparison between HBV group and HCV group according to serum HA. * Not significance: $>0.05$

\begin{tabular}{|l|l|l|l|}
\hline & HBV group & HCV group & P value \\
\hline $\begin{array}{l}\text { Hayluronic } \\
\text { acid }\end{array}$ & $57.6 \pm 16.5$ & $103 \pm 37.5$ & $0.97^{* *}$ \\
\hline
\end{tabular}

Table 6: Comparison between mild fibrosis and Significant fibrosis in the studied groups according to HA levels.

\begin{tabular}{|c|r|l|l|}
\hline \multirow{2}{*}{ Studied } & \multicolumn{2}{|l|}{ Level HA in fibrosis stages } & \multirow{2}{*}{} \\
\cline { 2 - 4 } groups & $\begin{array}{l}\text { Non- } \\
\text { Significant fibrosis }\end{array}$ & $\begin{array}{l}\text { Significant } \\
\text { fibrosis }\end{array}$ & \\
\hline HCV & $23.5 \pm 14.7$ & $188 \pm 161.6$ & $<0.001$ \\
\hline HBV & $33.9 \pm 22.1$ & $118 \pm 91.6$ & $<0.001$ \\
\hline
\end{tabular}

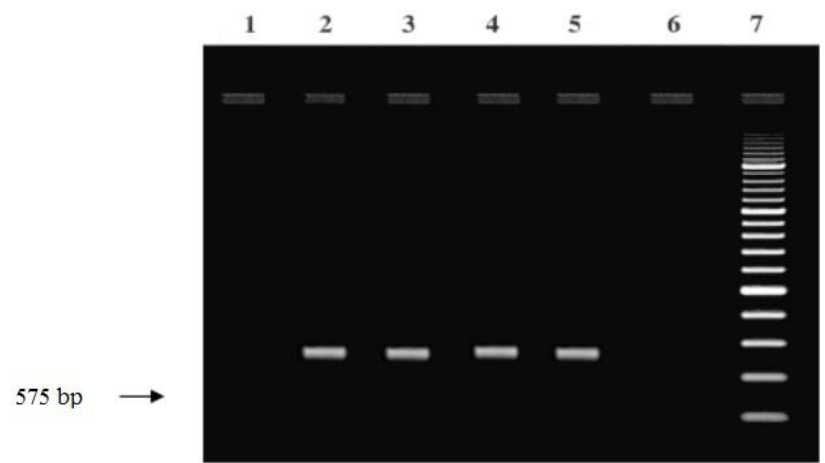

Figure 1: Detection of HBV-DNA by PCR. Lane 1- 6 serum samples from healthy individuals (negative control). Lanes 2, 3 and 4: serum samples from HBV patients group (positive samples). Lane 5: positive control, Lane 7: DNA marker (200bp DNA ladder).

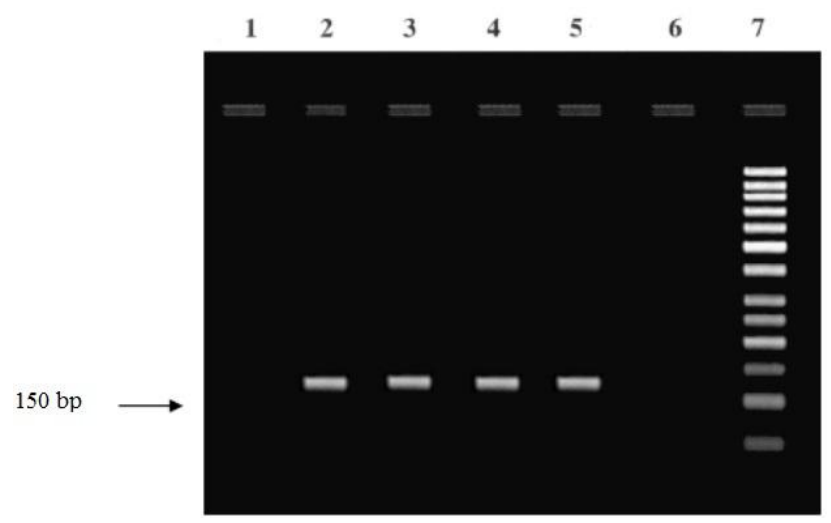

Figure 2: Detection of HCV-RNA by PCR. Lane 1- 6 serum samples from healthy individuals (negative control). Lane 5: positive control. Lanes 2, 3 and 4: serum samples from HCV patients group (positive samples), Lane 7: DNA marker (50bp DNA ladder).

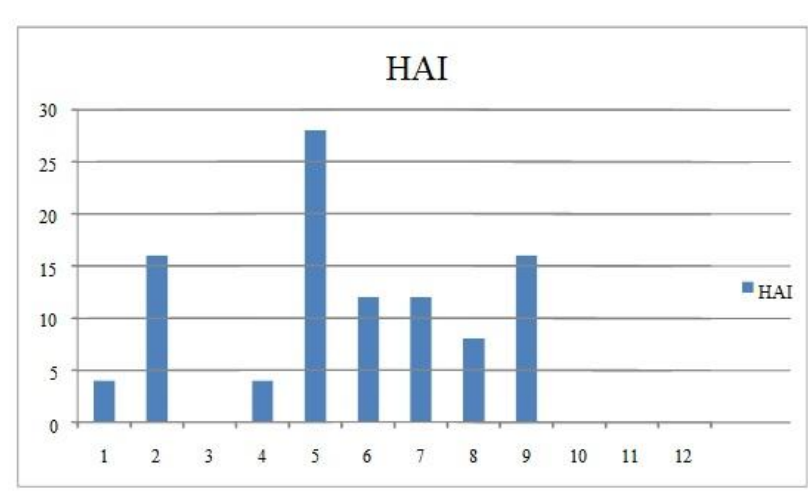

Figure 3: Characteristics of histological activity index (HAI) of patients with HBV (group HBV n=30) 


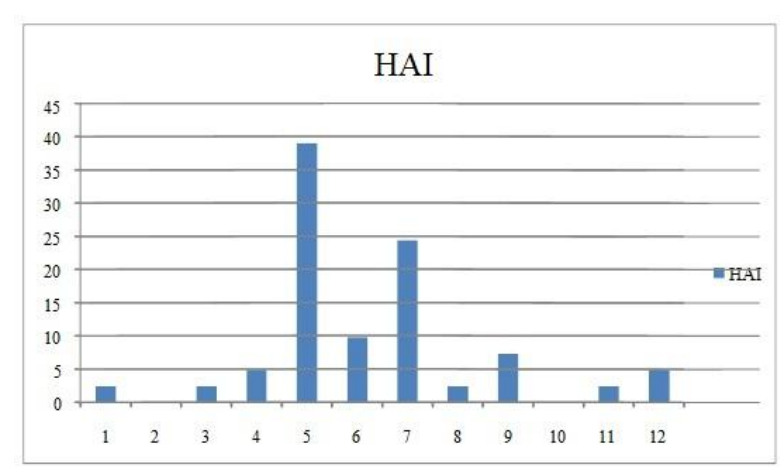

Figure 4: Characteristics of histological activity index (HAI) of patients with HCV (group HCV n=30)

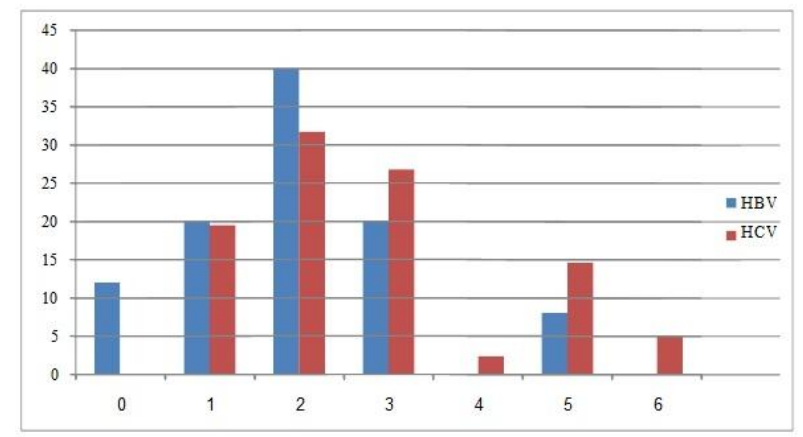

Figure 5: Characteristics of fibrosis grade of patients with HBV and HCV groups.

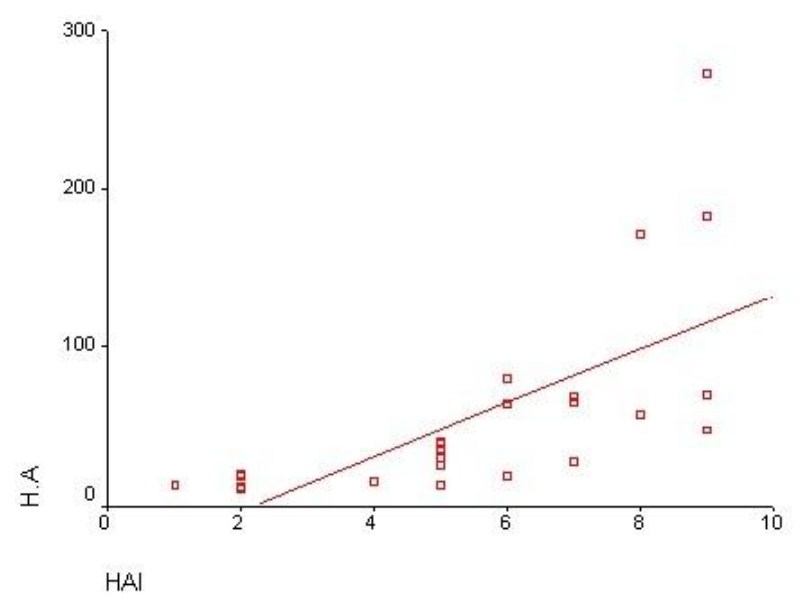

Figure 6: Correlation between levels of HA and HAI in patients of HBV.

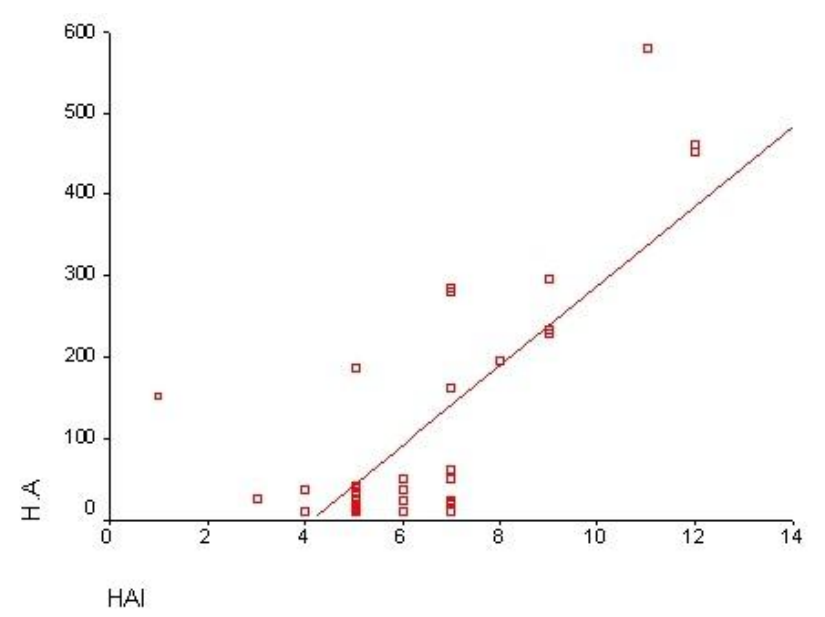

Figure 7: Correlation between levels of HA and HAI in patients of $\mathrm{HCV}$.

\section{Discussion}

Among important hepatitis associated risk factors reported were parenternal injection, dental manipulation and hospitalization. Blood transfusion seemed to have very minor role (Farghyaly and Barakat., 1992). The courses and outcomes of chronic hepatitis B virus infections were quite variable. Milder forms were nonprogressive or only slowly progressive and were usually accompanied by the loss of serum HBV DNA and sero conversion from hepatitis $\mathrm{B}$ envelop antigen to envelop antibody (anti-HBe) (Kreutz 2002). Manno et al., (2002) found no significant different regarding the survival of liver related deaths between chronic asymptomatic HBsAg carriers and controls after thirty years of follow up. In this study, hepatic transaminasis in patients of group B were normal in 97\% of chronic HBV patients and all patients were positive for HBV DNA using PCR. this in agreement with Lindh et al., (2000) who found that using PCR assays, the majority of patients with chronic HBV infection, including those who are hepatitis be antibody positive have detectable HBV DNA. HCV is a small enveloped RNA virus that is responsible for more than $90 \%$ of cases of partially transmitted none A, non B hepatitis (Cuthbert, 1997). Although acute infection with $\mathrm{HCV}$ may be asymptomatic, HCV infection can cause chronic liver disease such as chronic hepatitis and cirrhosis (Choo et al., 1987) and is involved in the hepatocellualr carcinoma (Kiysoawa et al., 1990). Many cases of hepatitis $\mathrm{C}$ were transmitted by blood transfusion or other modes of parenteral transfusion such as contaminated needles. Data from the center for disease control (USA) showed that only 6\% of patients report a history of blood transfusion, 46\% reported paranteral drug use. $10 \%$ sexual exposure and $2 \%$ a health care occupation; the remaining $36 \%$ were infected with 
unknown agents (Alter et al., 1991). Clearly, the most common identifiable risk factor is related to parenteral exposure, primarily intravenous drugs use and blood transfusion (Hadler and Margolis, 1989). ALT and AST were well recognized markers of hepatocellualr damage in patients with (HCV) infection (Yano et al., 1993). In the past decade, several investigators focused on developing non-invasive test for liver fibrosis (Wai et al., 2003). None of them proved to be perfect. Guechot et al., (1994) showed that hyaluronate had better correlation to the degrees of fibrosis than PIIIP in chronic liver disease. In the study by Oberti et al., (1997) serum hyaluronate level was considered the most sensitive test for screening in viral hepatitis B and C. Non-invasive methods to measure severity of liver injury are clinically important in Egypt where advanced liver disease from HBV and HCV is common and access to liver biopsy is limited. In addition, reliability of the biopsy to detect and measure hepatic pathology is not ideal. Our study demonstrated that in HBV, HA was well correlated to the degree of liver fibrosis and might be useful as a noninvasive diagnostic marker of fibrosis. This result is in agreement with Wyatt et al., (2002) who demonstrated that serum hyaluronate was the best predictor of extensive liver fibrosis and inflammation and it could discriminate subgroups of patients with chronic hepatitis B. Also, HA could be used as a non-invasive test to monitor these patients more closely with developing anti-viral agents in clinical trials (Montazeri et al., 2005). Serum hyaluronate as a direct marker of liver fibrosis appears to be the most promising one (Cadranelnet al., 2002). The studies have shown that hyaluronic acid increase in acute liver failure (Bramley et al., 1991), primary billiary cirrhosis, alcoholic liver disease and chronic hepatitis C (Plevris et al., 2000). Our study showed that significant fibrosis, and cirrhosis can be predicted by serum HA levels in patients with viral hepatitis infection (HBV or $\mathrm{HCV}$ ). This result is in agreement with (Zhang et al., 2008) who showed that Hyaluronan is a better fibrosis marker than laminin to diagnose children with advanced liver fibrosis (Xie et al., 2003).The significant decrease of hyaluronan level during therapy suggests anti- fibrotic effect of lamivudine in children with CHB. Lebenstejen et al., (2007) reported that lipid peroxides and protein carbonyl, as well as Hyaluronic acid levels increased with the grade of fibrosis. Moreover, protein carbonyl and hyaluronic acid levels correlated positively with lipid peroxide levels. These findings indicate that oxidative stress might contribute to S. HA and Hepascore cannot accurately stage hepatic Cross-linked high-molecular-weight HA had positive effects on the prevention of epidural fibrosis and the reduction of fibrotic tissue density. The efficacy of this agent should also be verified in further experimental and clinical studies (Isık et al., 2015).The increasing of HA level in our patients may be due to liver fibrosis which is the result of the imbalance between synthesis and degradation of the extracellular matrix. HA is one of the major components of the extracellular matrix glycosaminoglycan, often as the detection indicator of liver fibrosis. Serum hyaluronan levels are associated with Histopathological changes in chronic liver disease. Increasing concentration of hyaluronan in serum is associated with cirrhosis of the liver. HA can accurately reflect that the liver has generated fiber volume and status of liver cell damage. When chronic liver damage takes place, synthesis of HA is increased and the degradation is reduced, so that HA content in serum is increased and HA content is also correlated with the stage of hepatic fibrosis (Wang and Liang, 2010).

\section{Conclusion}

In conclusion our data indicated that serum hyaluronic acid had significant correlation and predictive value for the presence of significant liver fibrosis and inflammation comparing to the other variables. In addition it was able to discriminate extensive fibrosis and inflammation from their milder counterparts in patients with viral hepatitis. An increase in serum HA concentration above the predictive value is associated with liver fibrosis. HA can accurately reflect that the liver has generated fiber volume and status of liver cell damage. When chronic liver damage takes place, synthesis of $\mathrm{HA}$ is increased and the degradation is reduced, so that HA content in serum is increased and HA content is also correlated with the stage of hepatic fibrosis. Then Serum hyaluronate was the best predictor of extensive liver fibrosis and inflammation and it could discriminate subgroups of patients with chronic viral hepatitis.

\section{COMPETING INTERESTS}

Authors have declared that no competing interests exist.

\section{References}

Alberti A, Noventa F, Benvegnu L, Boccato S, Gatta A (2002). Prevalence of liver disease in a population of asymptomatic persons with hepatitis $C$ virus infection. Ann Intern Med; 137: 961-4.

Alberti A, Morsica G, Chemello L, Cavaletto D, Noventa F, Pontisso P (1992). Hepatitis C viraemia and liver disease in symptom-free individuals with anti HCV. Lancet; 340: 697-8. 
Alter MJ, Margolis HS and Hadler SC (1991). Hepatitis B. Evolving epidemiology and implications for control. Semin Liver Dis:84-92.

Bancroft, Choo QL, Kuo G and Stevens (1975). Histopathological stains and their diagnostic uses (Hardcover), Elsevier Health Science.192-193.,

Bramley PN, Rathbone BJ, Forbes MA, Cooper EH, Losowsky MS (1991). Serum hyaluronate as a marker of hepatic demngement in acute liver damage. J Hepatol: 8-13.

Cadranel JF, Mathurin P (2002). Prothrombin index decrease: a useful and reliable marker of extensive fibrosis? Eur J Gastroenterol Hepatol:1057-1059.

Choo QL, Kuo G, Weiner AJ,Overby LR, Bradley DW and Houghton M (1987). Isolation of a cDNA clone derived from blood-borne non-A, non-B viral hepatitis genome. Science. 244: 359- 362.

Cuthbert JA (1997). Hepatitis C: progress and prob lems. Clin. Microbiol. Rev: 505 - 532.

Engstorm-Laurent A, Loof L, Nyberg A, Schroder $\mathrm{T}$ (1985) Increased serum levels of hyaluronate in liver disease. Hepatology: 638-42.

Fraser JR, Laurent T, Pertoft H, Baxter E (2000). Plasma clearance, tissue distribution and metabolism of hyaluronan injected intravenously in the rabbit. Biochem J 1981: 415-24.

Farghaly AG and Barakat RM (1992). Association between chronic hepatitis $B$ Carrier state and schistosomiasis. J. Egypt Public Health Assoc. 67(56):607-21.

Isık S, Taşkapılıŏglu MÖ, Atalay FO, Dogan S( 2015). Effects of cross-linked high-molecular-weight hyaluronic acid on epidural fibrosis: experimental study.J Neurosurg Spine.22 (1):94-100.

Gressner AM, Bachem MG (1990). Cellular sources of noncollagenous matrix proteins: role of fatstoring cell in fibrogenesis. Semin Liver Dis: 30-46.

Gressner AM (1987). Measurement connective tissue parameters in serum for diagnosis and follow-up of liver fibrosis. Ann Clin Biochem: (Pt 3):283-92.

Hadler S and Margolis HS (1989). Viral hepatitis in: Evans AS (ed.). Viral infections in human: Epidemiology and control. New York: Plenum Medical Books. Pp. 375 - 79.

Hamid S, Ismail FW, Jafri W (2007). Hepatitis and the health care worker- a Pakistani perspective. J Coll Physicians Surg Pak: 240-5.

Heidelbaugh J and Bruderl M (2006). Cirrhosis and Chronic Liver Failure: Part I. Diagnosis and Evaluation. Am Fam Physician; 74; 5:756-762.

Kiyosawa K, Sodeyama T, Tanaka E, Gibo Y, Yoshizawa K, Nakano Y and Future D (1990). Interrelationship of blood transfusion non-A, non-B hepatitis and hepatocellular carcinoma: analysis by detection of antibody to hepatitis C virus. Hepatol: 671 675.

Knodell RG, Ishak KG, Black WC, Chen TS, Craig R, Kaplowitz N, Kiernan TW and Wolman J (1981). Formulation and application of a numerical scoring system for assessing histological activity in asymptomatic chronic active hepatitis. J. Hepatology:431-5.

Kreutz C (2002). Molecular, immunological and clinical properties of mutated hepatitis B viruses. J. Cell. Mol. Med: 113-143.

Lebenstejen DM, Skiba E, Sobaniec Lotowska ME, Kaczmarski M (2007). Serum hyaluronan and laminin level in children with chronic hepatitis B during long-term lamivudine treatment. Hepatogastroenterlolgy: 834-8.

McHutchison JG, Blatt LM, de Medina M, Craig JR, Conrad A, Schiff ER and Tong MJ (2000). Measurement of serum hyaluronic acid in patients with chronic hepatitis $\mathrm{C}$ and its relationship to liver histology. Consensus Interferon Study Group. J Gastroenterol Hepatol. 945-51.

Montazeri G, Estakhri A, Mohamadnejad M, Nouri N, Montazeri F, Mohammadkani A (2005). Prediction of Significant Fibrosis in HBeAg-Positive Patients With Chronic Hepatitis B by a Noninvasive Model. BMC Gastroenterology. 12(5):32.

Nyberg A, Engstrome-Laurent A, Loof L (1988) Serum hyaluronate in primary biliary cirrhosis: a biochemical marker for progressive liver damage. Hepatology: 152-6.

Oberti F, Valsesia E, Pilette C, Rousselet MC, Bedossa P, Aube C, Gallois Y, Rifflet H, Maiga MY, Penneau-Fontbonne D, Cales P (1997).Noninvasive diagnosis of hepatic fibrosis and cirrhosis. Gastroenterology.113:1609-1616.

Plevris JN, Haydon GH, Simpson KJ, Dawkes R, Ludlum CA, Harrison DJ, Hayes PC (2000). Serum hyaluronate- a non-invasive test for diagnosis liver cirrhosis. Eur J Gastroenterol Hepatol.12:1121-1127.

Plebani M, Burlina A (1991) Biochemical markers of hepatic fibrosis. Clin Biochem; 24:219-39.

Rihn B., Hussenet F., Detry MB., Catelle A and Faou AL (2000). Evaluation of a supplemental assay for the diagnosis of hepatitis $C$ virus infections. Int. J.Infect. Dis: $42-5$.

Silva GF, Coelho KI, Nishimura NF, Soares EC (2004). Progression of liver fibrosis in blood donors infected with hepatitis C virus. Rom J Gastroenterol: 2917.

Wai CT, Greenson JK, Fontana RJ, Kalbfleisch JD, Marrero JA, Conjeevaram HS, Lok AS (2003). A simple noninvasive index can predict both significant fibrosis and cirrhosis in patients with chronic hepatitis C. Hepatology.38(2):518-526. 
Wang $\mathrm{P}$ and liang (2010). Chemical composition and inhibitory effect on hepatic fibrosis of Danggui Buxue Decoction. Fitoterapia, 81(7):793-798.

Wong V, Caronia S, Wight D, Britton P, Palmer C, Alexander G (1995). Liver biopsy is essential in the management of patients with chronic hepatitis $\mathrm{C}$ virus infection. Gut; 36:A949-A50.

Wong VS, Hughes V, Trull A, Wight DG, Petrik J, Alexander GJ (1998). Serum hyaluronic acid is a useful marker of liver fibrosis in chronic hepatitis $\mathrm{C}$ virus infection. J Viral Hepatitis; 5:187-92.

Wyatt H A, Dhawan A, Cheeseman P, MieliVergani G, and Price J F (2002). Serum hyaluronic acid concentrations are increased in cystic fibrosis patients with liver disease, Arch Dis. Child .86:190-193.

Xie S B, Yao, J L, Zheng R Q, Peng X M, and Gao Z L (2003). Serum hyaluronic acid, procollagen type III and IV in histological diagnosis of liver fibrosis. Hepatobiliary Pancreat Dis. Int. 2: 69-72.

Yano M (1992). Advances in hepatitis C, seroepidemiology and natural history. J.Gastroenterol. Hepatol. 7: 549-550.

Zhang Y X, Wu W J, Zhang Y Z, Feng Y L, Zhou $X$ X, and Pan Q(2008). Noninvasive assessment of liver fibrosis with combined serum aminotransferase/platelet ratio index and hyaluronic acid in patients with chronic hepatitis B. World J Gastroenterol. 14:7117-7121. 